\title{
A Case Study on Influential Factors of Group Activities in Middle School English Classes
}

\author{
Yafei Wang \\ Schools of Humanities and Law \\ North China University of Technology \\ Beijing, China
}

\author{
Zhuyu Yuchi \\ Schools of Humanities and Law \\ North China University of Technology \\ Beijing, China
}

\begin{abstract}
Group activities could create a good language learning environment, while how the teachers design and practice them influences the results directly. This study is a case study to test whether the target high-school English teachers have been conducting effective classroom group activities. During the research, the researchers observed and interviewed the teachers and the students as well. Then the data were analyzed under the Activity Theory from six factors-subject, object, community, division of labor, rules and tools. The research purpose is to know how the factors affect group activities in different English classrooms. As a result, it is found that the subject, the object and the community are more important; besides, tools and division of labor have different influences on classroom group activities. Finally, it is suggested that teachers should carry out group activities with more diversity to bring students' intention and students should be encouraged to participate more actively in group activities and provide feedback to teachers.
\end{abstract}

Keywords-English classes; group activities; Activity Theory; middle schools

\section{INTRODUCTION}

Since the release of the new middle-school curriculum reform in 2007, the student-centered teaching model has been required to replace the original teacher-centered one. Classroom group activity has been playing a very important role in middle-school English teaching courses. This teaching method not only urges students to actively participate in studying but also enables students to communicate in English at any time.

Group activity is one of the most common forms of group collaborative methods that are used in classroom learning. Group activity is the process by which two or more students work together in order to achieve a common purpose [1]. It is a kind of teaching method derived from the background of the class teaching system. Under the premise of recognizing classroom teaching as the basic teaching organization form, the teacher takes the study group as an important promotion [2].

In the practice of foreign language teaching, group activities have been applied very frequently, and the teachers give a very high evaluation of the group interaction. Activity Theory has been broadly applied in the analysis of group activities.

The Activity Theory originated from the classical

This research is financially supported by the Social Science Foundation of Beijing (Grant No.: 16JYC014) and the Fundamental Research Funds for Universities Affiliated to Beijing (Grant No.: 110052971921/091). philosophy of Kant and Hegel, formed in Marx's dialectical materialism, proposed by Vygotsky, matured in the former Soviet psychologists Leontief and Luria, is a research result of social and cultural activity and social history [3]. The Activity Theory emphasizes the bridge role of activities in the process of internalization of knowledge and skills. The main focus of Activity Theory is not on the state of knowledge, but on the nature of people's participation in activities, the tools they use in their activities, the social and contextual relationships of the partners in the activities, the purpose of the activities, and the objects and results of the activities. The basic unit in the theory is an activity, which is often used in the teaching designs and is to a great extent based on the design of classroom group activities [4]. The scope of Activity Theory is very broad, and in this article, we are focusing on the Activity System, which is the fundamental unit in Activity Theory, which consists of three core components including subject, object and community and three secondary components including tools, rules and division of labor.

\section{RESEARCH DESIGN}

\section{A. Research Background}

Group activities have greatly changed the classroom teaching and the students' language acquisition. Foreign scholars gradually shifted the research focus to the effectiveness of group activities. Cohen pointed out that it is very important for teachers to play a proper role in group activities, to organize students well before the activities, and to carefully arrange the entire activities [5]. Stevick believes that compared with learning content and teacher's teaching strategies, students' emotional attitudes and interactions with teachers and classmates play a greater role in language learning Therefore, students should take the initiative to communicate in the classroom tasks, and actively participate in the task, which will improve the classroom completion rate [6].

In China, since the early 1990s, educational researchers have begun to study cooperative learning. The research on English classroom group activities is divided into two parts: theoretical research and experimental research. The theoretical researches mainly introduce the theoretical basis of group activities, the research results of foreign group activities, the significance and the role of group activities, and the advantages and disadvantages of group activities, etc. Experimental 
research mainly explores the main factors affecting group activities, the skills of group activities, and the role of group activities in improving students' English performance through teachers' own classes. There are also many researchers in China who have done researches and analysis on the factors that affect the effectiveness of group activities. Dong Youneng divided the influential factors into internal factors and external factors. He believes that students' personalities, attitudes and motivations are internal factors that affect the effectiveness of group activities. The roles played by teachers, internal relationships among team members, and topics of activities belong to external factors [7]. Liu Hejun conducted a study on the college English classroom group activities through questionnaires and interviews. Studies show that students' learning motivation is the most direct influential factor of group activities, and students' learning motivation is directly influenced by the role played by teachers, classroom topics, and class grouping [8].

According to the previous studies on classroom group activities, most of them are quantitative studies and theoretical studies. In this study, based on Activity Theory, we select two representative teachers to conduct case studies and explore the factors affecting the effective development of group activities.

\section{B. Research objects}

Two English teachers were chosen to be the research participants. One is Ada, who graduated from a normal university and has been engaged in English teaching for seven years since 2012. The other is Flora, who graduated from normal universities with bachelor's degree and master's degree. Since graduation, she has been teaching in a high school for nearly 30 years.

\section{Research questions}

In this paper, we mainly explore two questions. One is to analyze the factors that affect the effectiveness of group activities after analyzing how the two English teachers carry out classroom group activities, and the second is to explore how classroom group activities can be improved.

\section{Research method}

This study is a case study. Two English teachers, one from a junior high school and the other from a senior high school in different districts of Beijing, were chosen as participants. Classroom observation, questionnaire surveys, and interviews are used to do the research.

\section{ClASSROOM CASES}

\section{A. The cases from Ada's class}

\section{Case 1}

This lesson is Community Service, which is a listening class It is mainly about volunteer work to clean up the rubbish on the beach. The purpose is to cultivate students' awareness of protecting the community environment and to serve the community with practical actions.

In this lesson, Ada designed three group activities - the first activity in pre-listening was to introduce the topic of this lesson, asking students to tell experiences similar to the topic. (Ask Students (Ss for short) to read the poster and discuss three questions in pairs. The three questions were "What did they do like this before?" "Do you enjoy helping others in community?" and "Why”?) After that, every two-student group shared the answer using dialogues in the class. The second activity was practiced after listening to the materials. The students were required to retell the volunteer work to the other partners in a four-students group. (Ss suppose they were one of the three volunteers in the listening materials, and retell the volunteers' work to the class.) The third activity followed the second. The teacher shared her own volunteer work, and then asked the students to share their experiences (Ask Ss to talk about their volunteer work by drawing the mind map).

In this lesson, through the observation of the group activities that have been arranged and carried out, it showed that the teacher would explain the words before leading the students to group work, and guide the students to open their mouths, sharing their volunteer experiences in English. While students properly formed their speech in English and shared with their group members, they built up the confidence to communicate with the companions and retold their texts. Furthermore, during the process, the researchers also found that some students were engaged in the activity and shared their thoughts aloud more easily, but not having much attention to the grammar in their sentences; While the other type of participators were more likely to keep quiet and listened to the other classmates' sharing; There was a large portion of students who participated in the group activities but with little initiative and enthusiasm due to the lack of motivation. Although the first type of students focused more on the expression of their own ideas, neglecting the rules of pronunciation, intonation, grammar, etc., they provided an example for those who were unwilling to speak, and had played a very good leading role. Therefore, it is concluded that students' attitudes are very important in group activities.

\section{Case 2}

The module focuses on the Olympic Spirit of Faster, Higher and Stronger. The lesson is Never Give Up!, which is a reading lesson. This lesson tells of the 15-year-old Janek, who is maimed by an accident. However, with the encouragement and help of the explorer Marek, he toughly completes the North and South Arctic expeditions and becomes the world's youngest polar explorer.

In this class, Ada conducted three group activities. In the process of While-reading, students were required to obtain the theme through reading details, understand the content of the story and the character of the protagonist, enhance the students' thinking ability through questioning, and lead students to think deeply. In the group activities, the students were obviously not very familiar with the content of the text. Although they were all involved in the discussion, the answers were not detailed and the voice was low. Later, in the Post-reading, the teacher asked the students to repeat the task and share the story according to the mind map. In this activity, firstly the students listened to their groupmates' recounting, then shared their stories with the classmates' ideas blended in their understanding according to their reading. In the end, with the 
encouragement of the teacher and the help of the team members, each of the students who retold the story in their own group fully grasped the content of the article and was able to confidently share it with the class. Finally, in the "Think and Discuss" session, the teacher guided students to do group discussions by adopting a new way-the Carousel Activity (Guide Ss to think about "What was the best answer of Janek's life?" and "How do you think of him and why?"). After asking questions, the teacher sent out a form for each group. Each group filled in the corresponding questions according to the discussion in its own group, and then passed the completed form to the next group. The group also received the completed form from the previous group. Through this activity, the teacher's teaching design can stimulate discussion within and between groups, thus inspiring and diversifying students' thinking, and guiding students to have a deeper understanding of the characteristics and quality of characters. Such activities are a novel and effective way of group discussion.

In this lesson, the teacher took use of a new group activity to encourage students to think and participate in the class. Compared to the second activity in which students can discuss, express and share their ideas in front of the whole class, the group activities in the first case are not very successful, because the students were not fully prepared, hence they were not very confident.

\section{B. The cases from Flora's class}

Case 1

The textbook of the English class in this semester is the edition of English textbook of Peking Normal University for Grade Two of senior high school. This unit is mainly about Adventure. The teacher introduced various kinds of adventures at the very beginning.

The first lesson was given in Class 8. Flora mainly carried out one group activity. In this group activity, Flora asked the students to imagine that they themselves were on an island and discussed in groups what they would bring if they could only bring four items on the list, and explained why. The list includes a knife, a compass, an alarm, a box of matches, some ropes, two bottles of water, a blanket, a bottle of sun-blocking cream, a saw, an axe, some playing cards, a saucepan and a packet of biscuits. After intense discussion, some groups chose to bring a knife, because a knife can make a fire; two bottles of water, because water will keep people away from dehydration; a compass to tell directions and some playing cards to have fun in such a limited time. In addition, there were other groups who selected to bring an alarm to check the time and get up on time. Also, some groups preferred to bring a saw because they could cut wood to make boats.

The lesson in Class 9 is on the same topic. In this lesson, Flora carried out two group activities. At the beginning of the lesson, she invited students to write their own adventure experiences, discussed in groups, and shared the most wellstructured sentences written by the group members in the class. The second activity was the same as Class 8 to select the items they carried on the island.
It is found that senior high school students were more active in critical thinking, imagination and creativity than junior high school students. They were familiar with the dynamic discussion atmosphere and participated more actively in the group activities. Some of them were with a lot of passion in using new phrases or more complicated sentence structures in their discussions and flooded with good ideas. And the pronunciation, intonation, vocabulary and grammar of the students in this school were more natural and with fewer errors. However, the researchers also noticed that the girls in Class 9 participated more actively and performed with better quality than boys and some boys naturally mixed up with some Chinese words in their English language. Furthermore, the teacher was running an open-styled class that focused on students. Flora constantly showed video, music and various related pictures in the class to guide students to live in it, stimulated students' understanding and resonance of adventure, and encouraged students to be creative and imaginative in the discussion.

\section{Case 2}

After explaining the whole framework of adventure to the students, Flora began her course on Extreme Sports with six pictures. In this activity, Flora first introduced most of the extreme sports in English so that students would have some knowledge for the next session of the activity. After 5-minite group discussion, one student from each group was chosen to go to the blackboard. The teacher chose a picture. The other members in the same group described the picture in three words. The student who went to the blackboard guessed which extreme sport it was according to the vocabulary provided by his peers. This process repeated until all the pictures were finished. After that, Flora invited the whole class to watch Parkour videos together, and then discussed "What's that?" in the group.

The two activities were designed to stimulate the interest to the extreme sports of the students and the discussion could be carried out properly related to these topics. Through this process, students' understanding of the related vocabulary could be deepened.

\section{ANALYSIS OF THE FACTORS OF EFFECTIVE} IMPLEMENTATION OF TEACHERS' GROUP ACTIVITY DESIGN

Through the interview with Ada, we know that Ada believes that group activities must be based on the teaching content itself, and the main goal is to guide students' critical thinking ability and innovation ability. In Ada's view, in the process of group activities, the design of activities by teachers is the key to group activities. Teachers' lesson preparation, classroom organization and activity design are all crucial. It is believed that whether the design of group activities is practical and focusing on the knowledge will mostly affect the group activity's results. Ada regards group activities as a bridge to promote students' development, and the grouping of the activities is the most important part of building this bridge.

According to Ada's interview and Activity Theory, in the middle school classroom group activities, the subject-students and teachers and division of labor-the role of teaching arrangements, are very important. Furthermore, the teacher 
who is playing the role of leading and guiding in all the activities contributes the most to the effects. In her point of view, language acquisition builds cognitive development and vice versa.

Through the interview with Flora, it is concluded that her class is students-centered. Her idea is to learn by doing and learn by using. She thinks that setting up group activities in class is a very effective way to cultivate students' autonomous learning ability. In addition, Flora divided students with the same level into one group or grouped students with various levels into one according to different teaching objectives. On the question of "Which part is more important in group activities?", Flora believes that teacher-student cooperation is the most important. The degree of students' cooperation determines whether a class is efficient or not. However, it also requires a clear division of labor and arrangement of teachers. Flora believes that the teaching environment is one of the factors that affect the development of group activities. The class taken in a spacious environment may be less efficient due to noise and distance between students and teachers.

From Flora's interview and Activity Theory, we know that in the process of developing group activities in middle schools, the subject-students and teachers; the tools-teaching environment; the object-teaching objectives are the main factors affecting the development of group activities.

\section{SugGestions FOR THE TEACHERS AND THE STUDENTS}

According to the problems found in the study, the researchers put forward the following suggestions. Firstly, in group activities, teachers and students both play an active role. As teachers, they should constantly improve their teaching ideas and methods, actively encourage and guide students to participate in group activities. Students themselves should change the idea that the class only relies on teachers, and participate in learning and expressing themselves in the English classroom independently.

Secondly, in terms of grouping, students' personality, English level, performance and ability should be taken into consideration so that teachers could allocate the group members to avoid the contradiction among some students who are too talkative and some students who are too shy; students should attach importance to learning and actively participate in activities so as to find tasks more suitable for themselves and cooperate with other members of the groups to complete the activities.

Thirdly, in the design of group activities, teachers should focus on different teaching tasks to carry out group activities and develop students' abilities in different aspects; and students should actively participate in them to provide feedback for the teachers' designing.

In addition, the researchers put forward suggestions for the two teachers respectively.

First, it is suggested that Ada should pay attention to her own teaching arrangements, as well as students' autonomous participation and the idea of group activities, so as to improve the ability of teacher-student interaction.
Secondly, it is suggested that Flora could maintain the student-centered teaching concept, develop the students' ability to participate in the design of group activities and carry out more diverse and innovative group activities.

\section{CONCLUSION AND ENLIGHTENMENT}

In this study, the researchers studied the classes of Ada and Flora, both of whom are from middle schools in Beijing. After a series of studies, such as preliminary investigation, classroom analysis, questionnaire survey and interview, the factors affecting the development of English classroom group activities were analyzed under Activity Theory and suggestions for improvements were put forward. It is found that different English classes have different situations, and different teachers have their own unique teaching methods. We cannot evaluate all classes in a general way, but the development of group activities cannot be separated from the active guidance of teachers and the active cooperation of students. Under the requirements of the new curriculum reform, we hope that students would be the center of class, and students could be active in classroom learning and participation, especially in English classes. We hope that students' ability to grasp English could be enhanced if group activities could be more active and effective.

\section{ACKNOWLEDGMENT}

This research is financially supported by the Social Science Foundation of Beijing (Grant No.: 16JYC014) and the Fundamental Research Funds for Universities Affiliated to Beijing (Grant No.: 110052971921/091).

\section{REFERENCES}

[1] Xiong Shuhui, "Development of Activity Theory and Its Application in Second Language Acquisition”, Journal of Changchun University of Science and Technology, 2010,5(11): 99-100. (In Chinese)

[2] Zheng Liyun. "Study on English Classroom Group Activities” [D], East China Normal University, 2010. (In Chinese)

[3] Yang Yuan, "Group Activity Teaching Design and Practical Research”[D], Dissertation of Chongqing University, 2014.

[4] Rui Yechen, “Teaching Design of 'Integration and Practice' in Primary Mathematics on the Basis of Activity Theory", Dissertation of Yangzhou University, 2017. (In Chinese)

[5] Cohen A. D. Strategies in Learning and Using a Second Language[M], NY: Addison Wesley Longman Limited, 1998.

[6] Stevick, E. W. Teaching languages: A way and ways, Rowley, MA: Newbury House, 1980.

[7] Dong Youneng. “An Empirical Study of Group Activities in English Classroom”[D], Hubei University, 2006. (In Chinese)

[8] Liu Hejun. "An Empirical Study on the Factors Affecting the Effectiveness of Group Activities in College English Classroom”[D], Hangzhou: Zhejiang University, 2010. (In Chinese) 